\title{
Emerging Technologies in Library Systems
}

\author{
Mohammad Saqib \\ Khadija Abdullah Al Maskari
}

\author{
Middle East College \\ Middle East College
}

\begin{abstract}
Most of the libraries nowadays are using emerging technologies in their systems. They have started using Radio Frequency Identification (RFID) technology that has changed the library tasks to be working practically and conveniently. This system helps librarians and library users to use the library systems more easily and more securely. In this paper, we have studied the current library system with the issues and challenges that they faced and we have proposed a new system using emerging technologies. This system will track the books and will take care of them from thefts. Also, will track the user who borrowed the books by his registered details, till he returns the books. Also, we have implemented a system to be using library services by users themselves.
\end{abstract}

\section{Introduction}

People like to get information and knowledge for many things that happen around them. They get this information from each other and the historical stories and experience of older people. This knowledge and information can be lost anytime and not be able to retrieve them. For that people started to save them in different ways by writing them on rocks, papers, leaves and as now a day in the books. Before the books are saved in temples, but now they are stored in libraries.

A library is a place that provides knowledge for different users in different fields. Library users are from different age groups and cultures. They can use books, CDs, documents, maps, PCs, etc. To manage user requirements to be in a convenes and secured way we need to use Library Management Systems (LMS). LMS controlled many processes in the library started registering users until they check out from the library. Most of these systems changed the paper used to be in a systematic way. Check-in and out, registration, borrow and return books or CDs and other activities are saved in computers directly with no need for the usage of papers. Nowadays, the managing of those all happened smartly by using Smart Library Management Systems (SLMS). Users themselves can use these systems by themselves in many activities such as Check-in and out from the libraries, borrow and return the books or CDs.

Also, there are security cameras with smart technology. CCTV Camera system is used to support security systems by record videos that can be used in the future if there any security issues happen. All these videos are saved in a smart system as labels day by day and will contain the date and time with high quality. All this smart system will help librarians to manage their time, work and perfectly complete their activities. The most famous smart managing system used in libraries is Radio Frequency Identification (RFID) technology. It has become simple and easy to use by librarians and library users. It's used to check-in and out the library, borrow and return books, provide the details of the stock in store and many other things.

\section{Literature Review:}

Many literature reviews mention the using of Radio Frequency Identification (RFID) system in different fields in libraries as showing below: 


\section{Journal of Student Research}

Fourth Middle East College Student Research Conference, Muscat, Sultanate of Oman

(Younis, M.I. 2012) talked in his paper about a smart library management system based on an RFID technology that will help the librarian to do their task inconvenient, smart and practical way [3]. The technology Radio Frequency Identification (RFID) has been used since the 1970s as a data capturing technique. The RFID system has a host computer (Connected to a database), transponder and reader. The readers are placed in a place that can be recognized as the transponders. RFID tags are placed in books or CDs and they contain the item details. Those tags can be as an active, semi-passive and passive tag.

There is some difference between those tags. The active tags transmit signals and power the internal circuits by using battery power to send a signal to an RFID reader that will be on rang 100 feet and it can be increased to 300 feet. The Semi-passive tags, the internal circuit is powered by its internal batteries which used only to power this circuit. Only the passive tags don't have an internal battery connected to it. RFID transfer data throw the radio waves and this data will be read by the RFID reader. The RFID reader is a device that receives and transmits this wave signal and encodes the transfer data stored in the tags.

Semi-passive and active tags are very expensive and it used for asset tracking the long-range and the passive tags are providing short ranges and it's cheaper. To read the data from the tags by the passive reader, the antenna in the passive reader will emit electromagnetic energy that will be received by the passive tag's antenna. Then the tag's microchip will emit a radio signal from the electromagnetic energy by using a tag's antenna. Then the reader will interpret the signal and send it to a computer network as interpreted information that can be read by the user. Smart Library Management System (SLMS) consists of library users with cards that contain tags, books with the tag, identification devices (Readers), operator workstations (PC contains the system's modules and database server) and door lock (With alarm). In the system, each user is written on a passive tag as unique identification as (user_id). Also, each book is configured as (book tag) on a passive tag. The door lock and the reader (Attached to the entrance door) is connected to the PC through a reliable network. The other reader is used for borrowing and returning purposes (Figure 1).

Figure 1. Smart Library Management System (SLMS)

There are many features of using an RFID system in the SLMS:

- Unauthorized users will not be allowed to enter the library.

- Un-borrowed books will not be allowed to take it outside the library. If the user takes the book without register it, the alarm system in the door will start immediately.

- When users want to borrow books, they will need to identify themselves to the operator. Then the operator will enter the book in the system, and it will be as borrowed.

- Users with registered books when they enter or go out of the library no alarm will start at the entrance door.

- To return the book, the user will go to the borrowing counter and identify himself to the operator.

- The operator will register the book in the system as returned book and the book will be as unborrowed.

- With RFID users can remotely track the availability of the books.

Authors (Mr.S.Giridharan; Mr.S.Bala krishnan; Mrs.P.Hemalatha; 2018) in their paper (A Study on 
Smart Library Management System) talked about the using new system Radio Frequency Identification (RFID) technology in libraries. This system will be used to tracking books in the library to be tracking more efficient of the materials. With this system, the librarian will save their time in scanning the barcodes of the items.

RFID is using for communication and tracking items in the library by using radio waves that have the same concept as a cell phone. Serial numbers will be stored in the items and it contains information on a microchip that is attached to an antenna (RFID tag). The chip will transmit the identification information to a reader by the antenna. The information will be converted into digital information. The digital information will be passed to computers. RFID tags are fixed inside a book's back cover. Tags equipped in a programmable chip and an antenna. Each tag has an antenna and an engraved microchip with at least capacity with 64 bits.

RFID technology is a combination of radio -frequency-based technology and microchip technology. Radio Frequency (RF) is transmitting signals by using an electromagnetic spectrum. RFID will read the RF and transfer it to a transponder, an RF tag (reader).

The reader will convert the waves back into digital information and will pass it to computers that can analyze this information. The RFID technology is increasing efficiency, reducing cost, improve inventory control and provide security. This will relieve the librarian with routine work and operational tasks [6].

\section{Advantage and disadvantage of RFID system:}

\section{Advantage:}

- It's a comprehensive system.

- An effective system, save time, faster and more secure and effective system.

- Give a return on investment quickly.

- Anti-theft.

- Identify a large number of items.

\section{Disadvantage}

- It's expensive

- Some materials may create signal problems.

\section{Challenges and issues at Libraries:}

Libraries facing many challenges in providing a suitable place for library users. Bellow list of some of the library issues.

- People decline in reading.

A report published by the National Endowment for the Arts has titled "Reading at Risk" in 2004 because most people are not giving the reading any attention. This because they have moved from reading books and newspapers to electronic reading all their time. As people now are using mobiles that change their reading interests from books to read messages and view videos. This declining in 
reading will retreat the people from participation in others in cultural life and civic. With this issue, libraries lost many users who attend libraries for knowledge [1].

- Lack of qualified staff.

Most young people do not prefer to work in libraries as librarians, because they believe that this job does not allow them to be developed in their work. Some librarians do not know about solving simple issues as they don't know of it. For example, a librarian user doesn't know how to search for information from the web so the librarian will search for an assist from IT Support.

- Less training for librarians.

For managing daily technical issues in libraries, librarians need to get technical knowledge so they will be as helpful for library users. Most of the libraries are not providing this training for their librarians. This training will improve librarian knowledge and skills, especially management and IT skills. Also, they need to have good communication skills as dealing with users all the time.

- Lack of resource and lack of budget

Libraries should have enough budget to get recourses that are needed for the library, especially with the increase of users. Library resources will be Hardware and software resources.

- Hardware issues:

1. Lack of hardware capacity for automated functions in some libraries.

2. Internet access is slow because of choosing the wrong internet package and increasing internet usage.

3. Lack of computer upgrades and updated that will cause slowness of computer functions.

- Software issues:

1. Unsuitable library software that is used in some libraries for the library functions.

2. Using not friendly user software in libraries.

3. Software is not updating their packages as in the usual way.

- The lack of e-books on library website.

\section{Technological Evolution}

Libraries have for years witnessed a radical technological development in many of their systems. They have changed from the traditional system by using paper to be a digitization library. This has solved many issues in saving the loss of data, protect the environment by reducing the number of cut trees. For a long time, a human is collecting written knowledge and save it in different ways. There are about 30,000 clay tablets that date back more than 5,000 years in ancient Mesopotamia. Also, in China, before creating paper, they ware save the knowledge on plant fibres, mulberry bark, and silk after soaked them and laid out to dry.

Between $100 \mathrm{BC}$ - $105 \mathrm{AD}$ paper has been invented and then this paper is collected to be in one place as a book. Later on, those books were saved in one place called Libraries. Library word comes from a Latin word "Libraria" that is meant a place in a room or building that store books or other reading materials for public use or as a private user. In Sumer (a village located in Iraq) have the earliest known libraries from in 3200 B.C. To manage the huge number of books and users, new systems and technologies started to be used in libraries. Radio Frequency Identification (RFID) is one of the new systems used for data collection and auto Identification technology in the Smart 
Library Management System (SLMS). By using these radio waves, RFID technology allows the identification of a large number of books tagged. This technique doesn't need the line of sight to read and record the data. Also, the RFID technology tracking the books in the library and not allow any user to take them outside the library without being registered in the system.

The new technology saves user time to check the availability of the book on the library shelf. User checks in and out will be recorded by the RFID system every time they visit the library. Libraries offered electronic books on their web sites and they offered a good and convenient environment for users to use the library computers. Some libraries using cloud computing to offer information to users like in hospitals as providing information in time for medical technicians.

\section{New Technologies for Library System}

With RFID technology, the librarians will do their work comfortably and securely. This new system changes the barcode system to the RFID system that is more secure as it has a tracking and theft detection systems. Radio frequency identification (RFID) is a combination of microchip technology and radio-frequency-based technology. The information about the items is saved on a microchip in the tags that are fixed on books, CDs or user cards and it contains all their details [2].

By using RFID technology we have to implement a new system that allows library users to do their library activities by them-self. This new self-service system will be saved users and librarian time. Users will be able to search for the availability of books by them-shelf by searching for it with the author or book name. Also, users can borrow and return the books by using this system without waiting for the long queue in the registration corner. A self-service machine can help the librarian as it can collect the returned books and return them in their place on the shelves. The self-service system is working more active and it's a friendly use.

When a user wants to borrow a book he will go to the self-service machine and he will scan his card that has an RFID chip tag fixed on it. The system will identify the user and will show his details on the screen. The user will search the book located on the shelf. If the user wants to borrow the book, he will go to the self-service machine and identify himself, then he will scan the books in the same machine that will show the book details by using an RFID reader. The user can scan more than one book at a time as the RFID can read up to 100 feet.

After scanning the book, the user will confirm the borrowing process and he will receive a notification with the due date.

Also, when the user wants to return the books he will not need to go to the librarian to do it. The user can use the self-service machine and identify himself then chose the return option in the system. A small door (in the machine) will open to put the returned books (Figure 2).

This system will allow the librarian to do other library activates comfortably.

Figure 2. Book self-service

A new system that will help users that like to listen to stories, libraries have worked with coders and writers and created digital storytelling. This system will allow users to control the flow for the stories with a good area that has been designed carefully [4].

\section{Comparison of the current system with New Technologies:}


Still, many libraries used barcodes technology in the library to record the user and books in the system. All library activity is done manually by the librarian and this will takes a lot of their time and effort to complete their work. Sometimes it's difficult for them to search for a specific book as there is no tracking system allowed to search for it. The barcode will work with a direct line of sight to read the code by using laser technology. This technology can read and scan only one tag at a time and the barcode should be visible. This will lose librarian and user time by waiting for registration. Also, this technology does not have a memory to read and write data.

For that many libraries look forward to changing this old system to use the new system Radio frequency identification (RFID) technology. This new technology has solved many issues that are in barcode technology. RFID has not required a line of sight to identify the objects and it can read for long read range. This system has a tracking technique that will save the books from stolen. This system is the easiest and fastest in managing library activities that will reduce the stress of librarians and users as it will save their time. Check-in and check-out from the library are done faster. The RFID has a unique ID and it has a tracking system that is tracking items in minutes instead of hours [5].

The new technology, RFID is the best solution for many issues in libraries. This will make the library working in a smart easy way. The below figure showing the basic comparing between Barcodes and RFID systems (Figure 3).

Figure 3. Compering between RFID and Barcode

\section{Feasibility of Implementation of RFID into Libraries}

Implementing this new technology will make services easier to access and use, also will help users learn new technology and get new skills. We have done a feasibility study before implementing the RFID in a library. We check the budget availability, software and hardware requirement, type of items, availability of manpower, etc.

The implementation of RFID is a high cost, so we have done a cost-benefit analysis. Also, we do a data validation as it's very important to make sure it's valid before tagging work.

We have work on three visibility studies:

- Economical Feasibility

A study was done to check the impact of the system in libraries.

- Technical Feasibility

Check the technical resources available.

- Social Feasibility.

Checked the user acceptance of the new system.

In this project we used software and hardware carefully that will allowed us to implement the system perfectly.

- Software

- Database. 
- Operating system.

- Server.

- Hardware

- RFID Chips (Active RFID and Passive RFID tag).

- RFID Reader.

- PCs.

- Processor.

To get a good design for the project we have to get a good plan and knowledge for all requirements.

\section{Conclusion and Future work:}

Every day people are searching for new technics that make their life easier in any field in life. In the past, humans started saving and writing data in rooks and leaves, then it's improving to be saved as digital data in libraries. Many libraries now using a smart library management system (SLMS) to manage their systems. Starting by checking in and out of the library until using the security CCTV camera. In the future, the library will use the cloud computer to save their data as this technology will save money and space in the library system. We can get and order the cloud computing online and its service is available anywhere. This system will allow the libraries to avoid locally put up multiple equipment and servers dealing with software installs and hardware failure.

In the future, the library will use Artificial Intelligence (AI) in managing library systems. A user in the library will choose a book by a Digital Virtual Touch Screen. Then the system will search and bring the choosing books to the user table were his site. After using the book, the system will return the book on the shelf. This technology will save user and librarian time in search and return the book in its place.

Also in the future, users can use Virtual Reality to read books that in the library from anywhere in the world by $\log$ in to library sites.

\section{References:}

1. Top Ten Challenges Facing Public Libraries (2019) available from <https://www.tandfonline. com/doi/full/10.1080/01616846.2019.1608617?ai=1dy\&mi=hph1f7> [10 November 2019]

2. Libbest - Library RFID System (2019) available from < https://www.rfid-library.com/?gclid= Cj0KCQiAiNnuBRD3ARIsAM8Kmlunrp0gQMrkOZS_-R4j3dTej19ic2QTa7EPKEgF_5GcNpcVS 7m324QaAoL6EALw_wcB> [19 November 2019]

3. (PDF) SLMS: A smart library management system based on an RFID technology. Available from: https://www.researchgate.net/publication/235637059_SLMS_A_smart_library_manage ment_system_based_on_an_RFID_technology [accessed Nov 24 2019].

4. Current Technology Trends In Lib̆raries | Princh Blog (2019) available from $<$ https://princh.com/current-technology-trends-in-libraries/\#.Xd-ATm5uLIU> [23 November 2019]

5. (2019) available from <http://www.authorstream.com/Presentation/Blaze_Hyd-1670433-rfidlibrary-management-system-printronix/> [28 November 2019]

6. (2019) [online] available from <http://ajast.net/data/uploads/3031.pdf> [27 November 2019] 